\section{Oral clonidine pre- medication attenuates the haemodynamic effects associated with ketamine anaesthetic induction in humans}

Greg J. Doak MD FRCPC, Peter C. Duke MD FRCPC
Induction of anaesthesia is often associated with undesirable variations in blood pressure and heart rate. Clonidine has been demonstrated to attenuate many of these undesirable effects when used as a premedicant. Other alpha ${ }_{2}$ adrenergic agonists have been used to ameliorate the cardiostimulatory effects of ketamine in animals but there are few data on the use of this combination in humans. The effect of oral clonidine premedication, $5 \mu \mathrm{g} \cdot \mathrm{kg}^{-1}$ on the haemodynamic changes induced by iv ketamine was studied in 42 patient volunteers. Ninety minutes before surgery, patients randomly received clonidine $(C)$, diazepam $(D)$, or a placebo $(P)$ in a double-blinded fashion. Anaesthesia was induced with a ketamine infusion of 1 $\mathrm{mg} \cdot \mathrm{kg}^{-1} \cdot \mathrm{min}^{-1}$ until loss of consciousness. Heart rate and phasic blood pressure were measured noninvasively prior to induction, before and up to seven minutes after tracheal intubation. There were no differences in demographics or baseline vital signs among the three groups. With ketamine administration, increases in heart rate and blood pressure were less

\section{Key words}

ANAESTHETICS, INTRAVENOUS: ketamine;

COMPLICATIONS: hypertension;

INTUBATION, TRACHEAL: complications;

SYMPATHETIC NERVOUS SYSTEM: alpha adrenergic agonists, clonidine.

From the Department of Anaesthesia, University of Manitoba, Winnipeg, Manitoba.

Supported by The Manitoba Health Research Council.

Presented at the Annual Meeting of the Canadian

Anaesthetists' Society, June 25, 1991.

Address correspondence to: Dr. Greg J. Doak, Dept. of

Pharmacology, 6th Floor, Sir Charles Tupper Bldg., Dalhousie

University, Halifax, Nova Scotia, B3H 4H7.

Accepted for publication 29th March, 1993. in those patients given $C$ preoperatively than in those who received either $D$ or $P$. The peak increase in mean blood pressure was $39 \%(C)$ versus $70 \%(D)$ and $55 \%(P)(P<0.01)$. Heart rate increased by a maximum of $20 \%(C)$ versus $41 \%(D)$ and $46 \%(P)(P<0.01)$. We conclude that oral clonidine attenuates the hyperdynamic effects of anaesthetic induction with iv ketamine.

Linduction de l'anesthésie s'accompagne souvent de changements indésirables de la tension artérielle et de la fréquence cardiaque. En prémédication, on a démontré que la clonidine diminuait ces effets défavorables. D'autres agonistes alpha ${ }_{2}$ ont été utilisés chez l'animal pour atténuer les effets cardiostimulateurs de la kétamine, mais nous ne possédons que peu de données sur l'utilisation de cette association chez l'humain. Les effets de la clonidine orale en prémédication à la posologie de $5 \mu \mathrm{g} \cdot \mathrm{kg}^{-1}$ sur les changements hémodynamiques provoqués par la kétamine sont étudiés chez 42 patients volontaires. Quatre-vingt dix minutes avant la chirurgie, les patients recoivent au hasard et à double insu soit de la clonidine (C), du diazepam (D), ou un placébo (P). L'anesthésie est induite avec une perfusion de kétamine $1 \mathrm{mg} \cdot \mathrm{kg}^{-1} \cdot \mathrm{min}^{-1}$ jusqu'à la perte de conscience. La fréquence cardiaque et la tension artérielle sont mesurées de façon non invasive avant linduction, avant lintubation et jusqu'à sept minutes après celle-ci. On ne trouve pas de différences démographiques ou de paramètres vitaux initiaux entre les trois groupes. Avec ladministration de la kétamine, l'augmentation de fréquence cardique et de tension artérielle est moindre chez les patients qui ont reçu $C$ en prémédication que ceux qui ont reçu $D$ ou $P$. L'augmentation maximale de tension artérielle moyenne est de $39 \%$ (C) vs 70\% (D) et 55\% (P) $(P<0,01)$. Nous concluons que la clonidine orale atténue les effets hyperdynamiques de linduction de l'anesthésie à la kétamine iv.

The ideal intravenous induction agent should have a rapid onset and short duration of action while producing ade- 
quate and predictable anaesthesia. It should provide haemodynamic stability and be free of adverse effects. Induction agents such as thiopentone are often accompanied by hypotension followed by hypertension during laryngoscopy. Midazolam has similar effects when used as an induction agent ${ }^{1}$ and although high-dose narcotics may provide haemodynamic stability, they may have side effects such as bradycardia, chest wall rigidity, and postoperative respiratory depression. ${ }^{2}$

Ketamine, a non-barbiturate anaesthetic induction agent, produces a "dissociative" anaesthetic state characterized by a functional and electrophysiological dissociation between the limbic and thalamoneocortical systems. ${ }^{3}$ In addition to its anaesthetic properties, it provides profound analgesia at subanaesthetic doses. ${ }^{4}$ When used as an induction agent, it does not produce respiratory depression and airway reflexes are maintained. Despite causing some direct myocardial depression at higher doses, haemodynamic stability may be maintained in hypovolaemic patients due to its sympathomimetic actions. ${ }^{4}$ Ketamine is highly lipid soluble and has a rapid onset of action. After a bolus injection, its effects are relatively short-lived (10-20 min), with redistribution of the drug being mainly responsible for the rapid decrease in plasma concentrations. Despite many apparently desirable traits, ketamine has not enjoyed widespread use. In part, this may be related to its cardiostimulatory effects in normovolaemic patients, ${ }^{5,6}$ which may be unacceptable in some circumstances.

Clonidine is an oral antihypertensive agent which is known to reduce central sympathetic outflow via central alpha $_{2}$ adrenergic receptor stimulation. ${ }^{7}$ Clonidine has been shown to reduce the anaesthetic requirements of halothane ${ }^{8,9}$ and isoflurane, ${ }^{10}$ and to reduce the narcotic requirements for anaesthesia during coronary artery bypass surgery. ${ }^{11,12}$ In addition, clonidine is effective in blunting the tachycardia and hypertension associated with tracheal intubation. ${ }^{10,13,14}$

The sympatholytic activity and anaesthetic sparing action of clonidine in combination with ketamine, may approach the characteristics of the ideal drug combination for induction. In veterinary practice, ketamine is frequently combined with xylazine (an alpha $a_{2}$ adrenergic agonist similar to clonidine) to produce a smoother anaesthetic state. ${ }^{15-17}$ There are few data on the interaction of any alpha $a_{2}$ adrenergic agonists and ketamine in humans. ${ }^{18}$

The purpose of this study was to observe the early haemodynamic effects associated with induction of anaesthesia with ketamine in patients premedicated with oral clonidine to see if the usual hyperdynamic responses to induction with ketamine were attenuated by prior administration of clonidine. The doses of ketamine required for induction of anaesthesia in patients premedicated with clonidine, placebo or diazepam were compared to determine if there was any reduction in ketamine dose requirements in those patients receiving clonidine.

\section{Methods}

After approval by the Human Ethics Committee of the University of Manitoba and informed consent, 42 ASA 1 or 2 patients under $45 \mathrm{yr}$ of age, undergoing elective general or orthopaedic surgery, were recruited. Patients with severe cardio-respiratory, neurological or psychiatric disorders were excluded. Each patient was administered iv fluids $\left(1.5-2.0 \mathrm{ml} \cdot \mathrm{kg}^{-1}\right)$ while fasting and was randomly assigned to receive either diazepam $0.15 \mathrm{mg} \cdot \mathrm{kg}^{-1}$ (D), clonidine $5 \mu \mathrm{g} \cdot \mathrm{kg}^{-1}$ (C), or placebo (P) orally, $90 \mathrm{~min}$ before induction of anaesthesia. Identically appearing capsules containing specific amounts of one of the premedications were prepared by the pharmacy to ensure blinding of patients and investigators to the study drug.

Upon arrival in the operating room, each patient was prepared and monitored in the usual manner. Phasic blood pressure was measured by a noninvasive finger servo-plethysmomanometer device (Fin-a-Pres, Ohmeda). Systolic, diastolic and mean blood pressures and heart rate were recorded during the induction sequence. The sequence consisted of preoxygenation with $100 \%$ oxygen by face mask for three minutes, $i v$ d-tubocurarine $0.05 \mathrm{mg} \cdot \mathrm{kg}^{-1}$, and an infusion of ketamine at a rate of $1.0 \mathrm{mg} \cdot \mathrm{kg}^{-1} \cdot \mathrm{min}^{-1}$ until loss of consciousness. The total dose of ketamine required to induce anaesthesia was recorded. Succinylcholine, $1.5 \mathrm{mg} \cdot \mathrm{kg}^{-1}$, was administered to facilitate tracheal intubation and was followed by ventilation with $70 \%$ nitrous oxide and oxygen. A volatile agent was added, at the discretion of the attending anaesthetist, if inadequate anesthesia was evident or for control of hypertension.

Phasic blood pressure and heart rate were measured at nine intervals perioperatively: on the ward prior to receiving the preoperative medication (PREOP), at seven measurement intervals $\left(\mathrm{T}_{0}-\mathrm{T}_{6}\right)$ around induction, and in the recovery room (PARR). Time periods $T_{0}$ and $T_{1}$ represent values on arrival in the operating room (approximately $90 \mathrm{~min}$ after receiving the study drug) and before starting the ketamine infusion, respectively. Intervals $\mathrm{T}_{2}-\mathrm{T}_{6}$ represent time periods one minute post-induction, one minute post-intubation, and three, five, and seven minutes post-intubation, respectively. The remainder of the anaesthetic was conducted according to the discretion of the attending anaesthetist. All patients were interviewed in the recovery room by one of the investigators and any adverse psychological reactions were recorded and treated as required. Psychological phenomena were 
TABLE I Demographic characteristics of surgical patients given oral clonidine (C), diazepam (D) or placebo (P) preoperatively

\begin{tabular}{lllll}
\hline Group & $n$ & Male.female & Age $(y r)$ & Weight $(\mathrm{kg})$ \\
\hline C & 14 & $9: 5$ & $26.3 \pm 6.2$ & $77.9 \pm 16.3$ \\
D & 14 & $5: 9$ & $27.0 \pm 6.3$ & $73.4 \pm 12.4$ \\
P & 14 & $8: 6$ & $30.2 \pm 7.4$ & $76.5 \pm 18.0$ \\
\hline
\end{tabular}

Values are means $\pm S D$.

No significant differences among groups.

categorized as described by Ramsubramanian $e t$ al.,* according to the presence or absence of perceptive disorders (dreams, hallucinations, delirium, or confusion) and affective disorders (depression, anxiety, fear).

The study groups $(C, P$, and $D)$ were compared using analysis of variance for repeated measures to detect differences within and between groups for changes in heart rate and blood pressure. Duration of anaesthesia, ketamine dose and demographic variables were compared using Tukey's Studentized Range test. The incidence of psychological side effects, patient acceptance of the anaesthetic experience, and the incidence of requirement of isoflurane supplementation were analyzed by Chi-square. A $P$-value of $<0.05$ was considered significant and was adjusted to $P<0.01$ (Bonferroni's correction) in the case of multiple comparisons.

\section{Results}

The study groups, each consisting of 14 patients, were not different with respect to demographic variables (Table I). Heart rate (HR) and systolic (SBP), diastolic (DBP), and mean (MBP) blood pressure changes for the measurement intervals are shown in Table II (all results mean $\pm S D$ ). Before receiving any study drug (PREOP) there were no differences in any of the measured variables among the groups and these were utilized as a baseline with which the other interval data $\left(\mathrm{T}_{0}-\mathrm{T}_{6}\right.$ and PARR) were compared. Clonidine-treated patients had lower heart rates $(P<0.01)$ than patients receiving placebo at all subsequent intervals until PARR and their heart rates were lower than those of the diazepam group at $T_{2}, T_{3}$, and $T_{6}$ (Figure 1). Group $C$ patients tended to arrive in the operating room $\left(\mathrm{T}_{0}\right)$ with a heart rate below baseline; however, this did not reach statistical significance when corrected for multiple comparisons (58 \pm 11 vs $69 \pm 7, P=0.019$ ). Heart rate changes associated with induction occurred later and were of lesser magnitude in Group C than in Groups D and P. Clonidine

* Ramsubramanian R, Rawle PR, Verma R. Attenuation of psychological effects of ketamine anesthesia by midazolam: a dose-response study. Anesth Analg 1988; 67: S182.
TABLE II Haemodynamic measurements (mean \pm SD) before, during, and after induction with intravenous ketamine

\begin{tabular}{|c|c|c|c|c|}
\hline & $\begin{array}{l}H R \\
\left.\text { (beats } \cdot \min ^{-1}\right)\end{array}$ & $\begin{array}{l}S B P \\
(m m H g)\end{array}$ & $\begin{array}{l}D B P \\
(m m H g)\end{array}$ & $\begin{array}{l}M B P \\
(m m H g)\end{array}$ \\
\hline \multicolumn{5}{|c|}{ PREOP } \\
\hline $\mathrm{C}$ & $69 \pm 7$ & $118 \pm 12$ & $74 \pm 13$ & $88 \pm 12$ \\
\hline D & $70 \pm 11$ & $118 \pm 15$ & $73 \pm 9$ & $88 \pm 9$ \\
\hline $\mathbf{P}$ & $70 \pm 11$ & $115 \pm 10$ & $75 \pm 8$ & $88 \pm 8$ \\
\hline \multicolumn{5}{|c|}{$T_{0}$ (arrival in $O R$ ) } \\
\hline $\mathrm{C}$ & $58 \pm 11^{\mathrm{b}}$ & $118 \pm 19^{\mathrm{a}}$ & $65 \pm 12$ & $78 \pm 14^{\mathrm{a}}$ \\
\hline D & $69 \pm 12$ & $137 \pm 23$ & $75 \pm 17$ & $95 \pm 19$ \\
\hline $\mathrm{P}$ & $76 \pm 15$ & $140 \pm 20$ & $73 \pm 12$ & $92 \pm 11$ \\
\hline \multicolumn{5}{|c|}{$T_{1}$ (start of induction) } \\
\hline $\mathrm{C}$ & $60 \pm 11^{b}$ & $117 \pm 22^{\mathrm{a}}$ & $69 \pm 13^{c}$ & $81 \pm 14^{\mathrm{a}}$ \\
\hline D & $71 \pm 12$ & $145 \pm 26$ & $81 \pm 25$ & $102 \pm 27$ \\
\hline$P$ & $75 \pm 10$ & $145 \pm 17$ & $77 \pm 15$ & $98 \pm 10$ \\
\hline \multicolumn{5}{|c|}{$T_{2}(I$ min post-induction $)$} \\
\hline C & $70 \pm 13^{a}$ & $147 \pm 32^{\mathrm{a}}$ & $93 \pm 23^{c}$ & $112 \pm 23^{\mathrm{a}}$ \\
\hline $\mathrm{D}$ & $84 \pm 17$ & $187 \pm 31$ & $116 \pm 28^{d}$ & $142 \pm 29^{d}$ \\
\hline$P$ & $95 \pm 19$ & $171 \pm 21$ & $104 \pm 18$ & $127 \pm 19$ \\
\hline \multicolumn{5}{|c|}{$T_{3}(1 \mathrm{~min}$ post-intubation $)$} \\
\hline C & $78 \pm 19^{\mathrm{a}}$ & $163 \pm 31^{a}$ & $101 \pm 21^{c}$ & $123 \pm 23^{\circ}$ \\
\hline D & $98 \pm 20$ & $196 \pm 32$ & $120 \pm 28$ & $149 \pm 30^{d}$ \\
\hline$P$ & $103 \pm 19$ & $181 \pm 22$ & $109 \pm 17$ & $136 \pm 19$ \\
\hline \multicolumn{5}{|c|}{$T_{4}(3 \mathrm{~min}$ post-induction $)$} \\
\hline $\mathrm{C}$ & $82 \pm 23^{b}$ & $153 \pm 38^{a}$ & $96 \pm 24^{c}$ & $116 \pm 27^{\mathrm{a}}$ \\
\hline D & $93 \pm 18$ & $176 \pm 27$ & $108 \pm 20$ & $133 \pm 22$ \\
\hline $\mathbf{P}$ & $97 \pm 24$ & $176 \pm 27$ & $104 \pm 18$ & $131 \pm 20$ \\
\hline \multicolumn{5}{|c|}{$T_{5}(5$ min post-induction $)$} \\
\hline C & $83 \pm 18^{\mathrm{b}}$ & $142 \pm 33^{a}$ & $90 \pm 23^{\mathrm{a}}$ & $108 \pm 22^{\mathrm{a}}$ \\
\hline $\mathrm{D}$ & $94 \pm 16$ & $161 \pm 38$ & $102 \pm 28$ & $125 \pm 31$ \\
\hline$P$ & $101 \pm 19$ & $168 \pm 20$ & $103 \pm 13$ & $125 \pm 13$ \\
\hline \multicolumn{5}{|c|}{$T_{6}(7$ min post-induction $)$} \\
\hline $\mathrm{C}$ & $75 \pm 14^{\mathrm{a}}$ & $126 \pm 28^{a}$ & $77 \pm 18^{\mathrm{a}}$ & $92 \pm 20^{\mathrm{a}}$ \\
\hline D & $90 \pm 16$ & $145 \pm 31$ & $89 \pm 26$ & $110 \pm 28$ \\
\hline $\mathbf{P}$ & $95 \pm 16$ & $160 \pm 18$ & $97 \pm 9$ & $119 \pm 11$ \\
\hline \multicolumn{5}{|c|}{$P A R R$} \\
\hline C & $77 \pm 13$ & $127 \pm 13$ & $80 \pm 10$ & $96 \pm 10$ \\
\hline D & $77 \pm 12$ & $129 \pm 18$ & $79 \pm 11$ & $95 \pm 13$ \\
\hline $\mathbf{P}$ & $81 \pm 9$ & $131 \pm 17$ & $78 \pm 12$ & $96 \pm 13$ \\
\hline
\end{tabular}

$n=14$ pts. in each group. Bonferroni's correction applied for multiple comparisons. ${ }^{\mathrm{a}} \mathrm{P}<0.01 \mathrm{C}$ vs $\mathrm{D}$ and $\mathrm{P} ;{ }^{\mathrm{b}} \mathrm{P}<0.01 \mathrm{C}$ vs $\mathrm{P}$ only; ${ }^{\mathrm{c} P}<$ $0.01 \mathrm{C}$ vs $\mathrm{D}$ only; ${ }^{\mathrm{d} P}<0.01 \mathrm{D}$ vs $\mathrm{P}$ only. $\mathrm{HR}=$ heart rate, $\mathrm{SBP}=$ systolic blood pressure, DBP $=$ diastolic blood pressure, $\mathrm{MBP}=$ mean blood pressure, PREOP $=$ on the ward, prior to receiving premedication; $T_{0}=$ upon arrival in the $O R, T_{1}=$ prior to starting induction sequence, $T_{2}=1 \mathrm{~min}$ post-induction, $T_{3}=1 \mathrm{~min}$ postintubation, $T_{4}=3 \mathrm{~min}$ post-intubation, $T_{5}=5 \mathrm{~min}$ post-intubation, $T_{6}$ $=7 \mathrm{~min}$ post-intubation, $\mathrm{PARR}=$ discharge from post-anaesthesia recovery room.

was more effective than either diazepam or placebo ( $P$ $<0.01)$ in attenuating the increase in mean blood pres- 


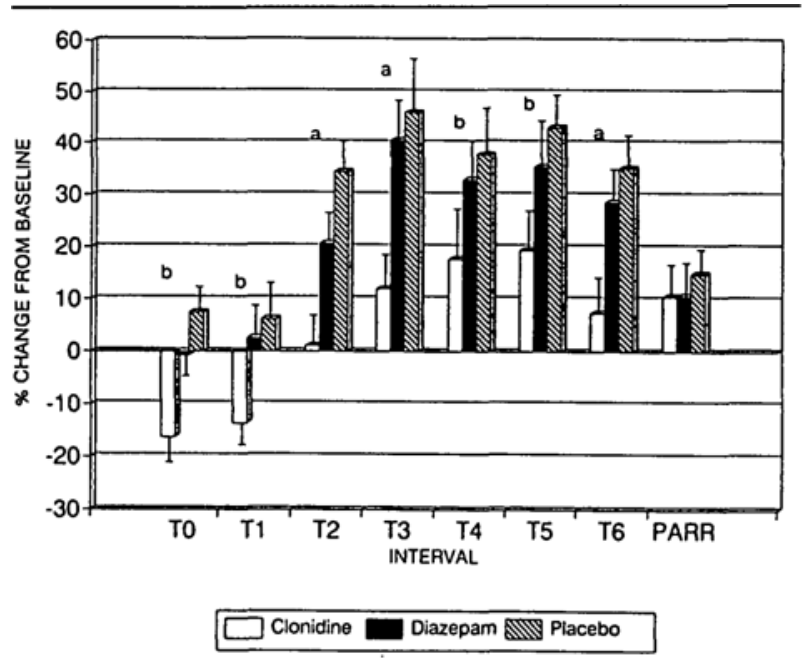

FIGURE I Heart rate (bpm) changes during ketamine induction, expressed as a percentage change from baseline (PREOP). Values $=$ mean $\pm \mathrm{SEM}, \mathrm{N}=14$ patients per group, $\mathrm{a}=P<0.01 \mathrm{C}$ vs $\mathrm{D}$ and $\mathrm{P}, \mathrm{b}=P<0.01 \mathrm{C}$ vs $\mathrm{P}$ only, $\mathrm{PREOP}=$ on the ward, before receiving premedication, $T_{0}=$ upon arrival in the $O R, T_{1}=$ prior to starting induction sequence, $T_{2}=1 \mathrm{~min}$ post-induction, $T_{3}=1 \mathrm{~min}$ postintubation, $T_{4}=3 \mathrm{~min}$ post-intubation, $T_{5}=5 \mathrm{~min}$ post-intubation, $\mathrm{T}_{6}=7 \mathrm{~min}$ post-intubation, PARR $=$ discharge from post-anaesthesia recovery room.

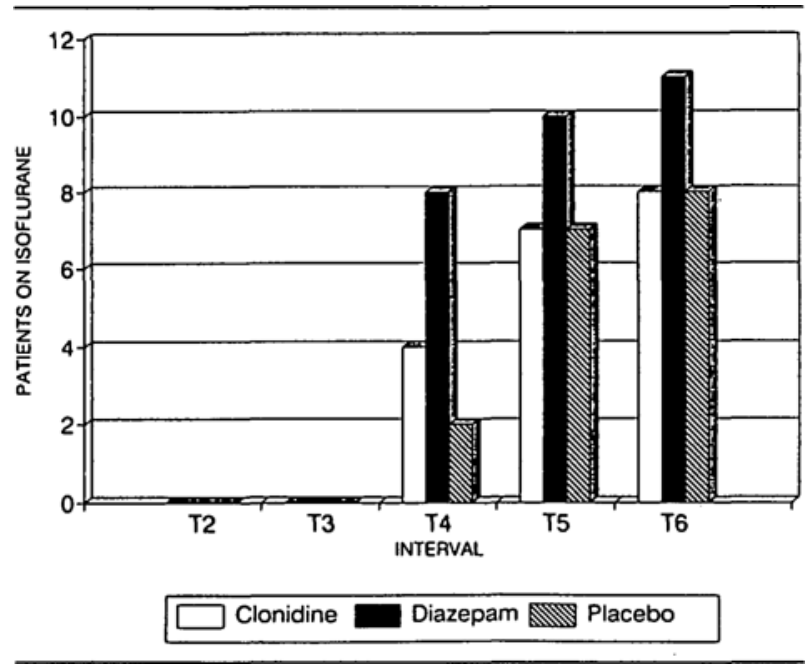

FIGURE 3 Frequency of requirement for isoflurane intervention. No significant differences. $T_{2}=1 \mathrm{~min}$ post-induction, $T_{3}=1 \mathrm{~min}$ postintubation, $T_{4}=3 \mathrm{~min}$ post-intubation, $T_{5}=5 \mathrm{~min}$ post-intubation, $\mathrm{T}_{6}=7 \mathrm{~min}$ post-intubation.

sure (Figure 2) during the preinduction period $\left(\mathrm{T}_{0-1}\right)$ and that associated with induction and intubation $\left(\mathrm{T}_{2-6}\right)$. The patterns with systolic and diastolic blood pressures were similar (Table II). The average peak MBP in the clonidine-treated group was $123 \pm 23$, an increase of 35 $\mathrm{mmHg}(+39 \%)$ over baseline. Heart rate increased to

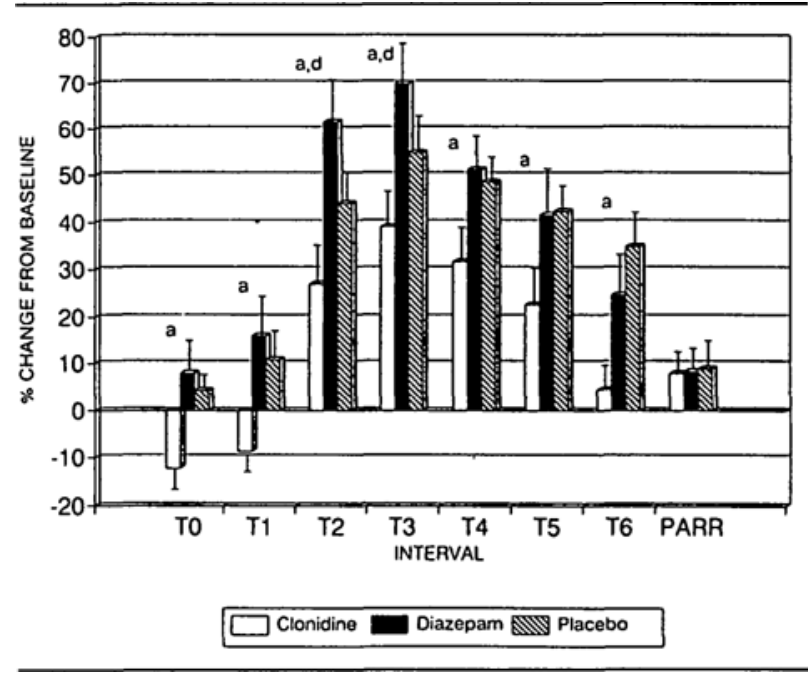

FIGURE 2 Mean blood pressure $(\mathrm{mmHg})$ changes during ketamine induction, expressed as a percentage change from baseline (PREOP). Values $=$ mean $\pm \mathrm{SEM}, \mathrm{N}=14$ patients per group, $\mathrm{a}=P<0.01 \mathrm{C}$ vs $\mathrm{D}$ and $\mathrm{P}, \mathrm{d}=P<0.01 \mathrm{C}$ vs $\mathrm{P}$ only, $\mathrm{PREOP}=$ on the ward, prior to receiving premedication, $T_{0}=$ upon arrival in the $O R, T_{1}=$ prior to starting induction sequence, $T_{2}=1 \mathrm{~min}$ post-induction, $T_{3}=1 \mathrm{~min}$ post-intubation, $T_{4}=3 \mathrm{~min}$ post-intubation, $T_{5}=5 \mathrm{~min}$ postintubation, $T_{6}=7$ min post-intubation, $\mathrm{PARR}=$ discharge from postanaesthesia recovery room.

TABLE III Ketamine total dose requirements ( $\mathrm{mg}$ ) and adjusted for weight $\left(\mathrm{mg} \cdot \mathrm{kg}^{-1}\right)$ in patients receiving premedication with oral clonidine (C), diazepam (D), or placebo (P)

\begin{tabular}{lll}
\hline & Total dose $(\mathrm{mg})$ & Adjusted dose $\left(\mathrm{mg} \cdot \mathrm{kg}^{-1}\right)$ \\
\hline $\mathrm{C}$ & $152 \pm 35$ & $1.95 \pm 0.25^{*}$ \\
$\mathrm{D}$ & $159 \pm 48$ & $2.14 \pm 0.41$ \\
$\mathrm{P}$ & $187 \pm 65$ & $2.39 \pm 0.39$ \\
\hline
\end{tabular}

Values are means $\pm \mathrm{SD}$.

${ }^{*} P<0.05, \mathrm{C}$ vs $\mathrm{P}$.

an average peak of $83 \pm 18 \mathrm{bpm}$ which was $14 \mathrm{bpm}$ (20\%) above baseline. Figure 3 is a histogram of the frequency of the requirement for intervention with a volatile anaesthetic. No patient required isoflurane until $T_{4}$, three minutes after intubation and there were no differences among the three groups.

The average ketamine dose requirements for each group were calculated (Table III). Although the average total ketamine doses were not different among the groups, when corrected for weight $\left(\mathrm{mg} \cdot \mathrm{kg}^{-1}\right)$, Group C patients required less ketamine than Group $P(1.95 \pm 0.25$ vs $2.39 \pm 0.39, P<0.05$ ). There was no difference between Group C and Group D.

Figure 4 is a histogram showing the number of patients in each group exhibiting specific psychological phenomena in the recovery room. There were no differences for 


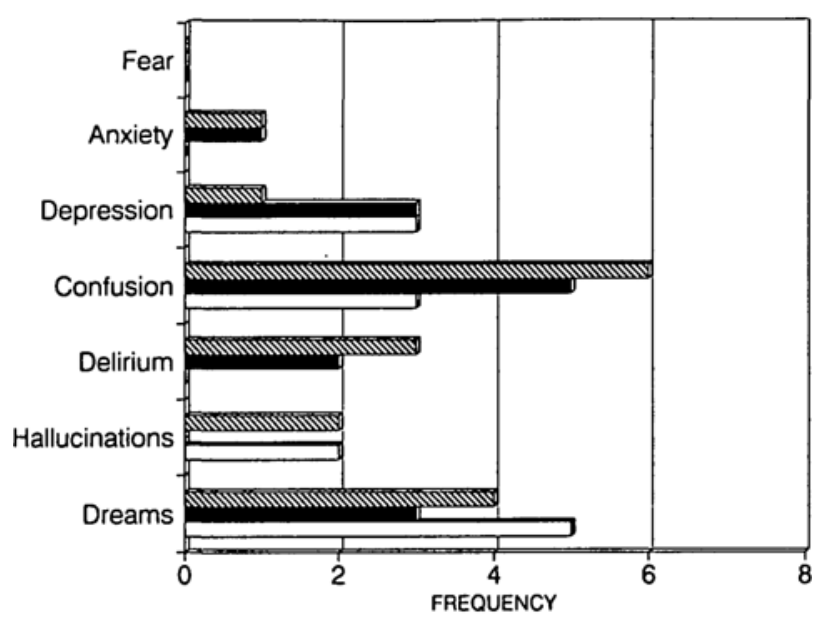

Clonidine Diazepam Placebo

FIGURE 4 Incidence of postoperative psychological phenomena in each group. No significant differences.

frequencies of these side effects detected among the groups. Most of the psychological side effects were mild and did not require treatment; however, there were three patients (one per group) who required $i v$ midazolam in the recovery room because of agitation ascribed to hallucinations. The duration of anaesthesia (induction until tracheal extubation) was $116 \pm 46,125 \pm 40$ and 102 \pm 39 min for Groups C, D and P, respectively (NS).

All patients were interviewed on the day after anaesthesia and were questioned again about psychological disturbances while in the recovery room or after. Patients were also asked if they would have the same anaesthetic again if given a choice. Of patients who had received clonidine, 12/14 would have the same anaesthetic again, compared with $11 / 14$ who had received diazepam and $7 / 14$ for placebo (NS).

\section{Discussion}

Clonidine attenuates the rise in heart rate and blood pressure associated with induction of anaesthesia using $i v$ ketamine. It does not, however, eliminate the cardiostimulatory effects which agrees with a recent study by Munro et al. ${ }^{18}$ Oral clonidine premedication may be useful to attenuate the cardiostimulatory effects of ketamine in healthy patients but cannot be relied upon to protect against unwanted increases in heart rate and blood pressure in predisposed patients. Many patients required isoflurane supplementation in response to movement and to control undesirable haemodynamic changes. The frequency of requirement for isoflurane supplementation increased with time. This may have been due to decreasing depth of anaesthesia, reflecting the relatively short duration of action of a single dose of ketamine. ${ }^{4}$ Clonidine has been shown to reduce the MAC of volatile anaesthetics ${ }^{8-10}$ and decrease narcotic requirements during coronary artery bypass surgery. ${ }^{11,12}$ Although the patients who received clonidine required less ketamine to induce anaesthesia than those who received diazepam or placebo, we did not specifically examine the MAC requirements following induction of anaesthesia.

The mechanism of clonidine's attenuation of the sympathomimetic effects of ketamine can only be speculated on from this study. The mechanism of the ketamineinduced tachycardia and hypertension is likely multifactorial. ${ }^{19}$ At high doses, ketamine has a direct myocardial depressing effect. This is counteracted in the intact organism by a central sympathetic stimulatory effect which increases circulating catecholamine concentrations. This sympathetic discharge may result from central inhibition of catecholamine reuptake. Inhibition of reuptake of circulating catecholamines also contributes to the increase of plasma concentrations. ${ }^{20}$ It is possible that the partial attenuation of the hypertension and tachycardia by clonidine is a result of a functional antagonism of ketamine's centrally mediated sympathetic discharge by a presynaptic alpha $_{2}$ adrenergically mediated inhibition of catecholamine release or by a postsynaptic alpha ${ }_{2}$ adrenergically mediated depression of the vasomotor centres in the brain. The effectiveness of either mechanism would be incomplete, as the peripheral action of ketamine to inhibit catecholamine reuptake would still be operative. This may explain why clonidine was unable to eliminate completely the cardiostimulatory effects of ketamine.

It is unlikely that differences in doses of ketamine among the groups had any effect on the magnitude of the haemodynamic changes observed as there appears to be little variation in the peak hypertensive response achieved using ketamine with doses greater than 1 $\mathrm{mg} \cdot \mathrm{kg}^{-1} \cdot{ }^{21}$ The possibility of a shortened duration of hypertension and tachycardia in those patients who received clonidine, secondary to a decreased ketamine dose, cannot be excluded. It is worth noting the haemodynamic state of the patient before induction of anaesthesia $\left(\mathrm{T}_{0}\right.$, $T_{1}$ ). The clonidine-treated patients arrived in the OR drowsy but alert. More importantly, the MBP was unchanged from baseline, whereas patients in the other groups had a marked elevation of MBP (Table II). This suggests that clonidine was a more effective sedative than diazepam and more effectively blocked the tachycardia and hypertension associated with preoperative anxiety.

Ketamine was generally well tolerated by patients receiving clonidine. Most patients reported a positive experience and the incidence of postoperative psychological phenomena was not increased in those patients receiving 
clonidine/ketamine compared with those receiving placebo/ketamine (Figure 4). Although no comparison of psychological phenomena associated with other anaesthetic regimens was made, this at least suggests that clonidine does not interact adversely with ketamine in this regard.

Since the introduction of ketamine into clinical use, many drugs have been used with it in an attempt to ameliorate the undesirable hypertension and tachycardia. Dundee $e t$ al. specifically examined promethazine, practolol, phentolamine, practolol/phentolamine, hexamethonium, procainamide, verapamil, and labetalol. ${ }^{22,23}$ They found that none of these was reliable in preventing both the tachycardia and the hypertension. Labetalol was most promising, being very effective in controlling the chronotropic action of ketamine but was inconsistent in controlling the increase in blood pressure.

Benzodiazepines, including diazepam and midazolam, have recently been employed to attenuate some of the hyperdynamic effects of ketamine but the results have been variable. Tuman et al. ${ }^{24}$ compared diazepamketamine anaesthesia with high-dose fentanyl in patients premedicated with diazepam, who underwent cardiac surgery. They found the haemodynamic changes associated with induction, intubation, and sternotomy to be comparable with those associated with high-dose fentanyl. On the other hand, Marlow et al. ${ }^{25}$ reported a high incidence (25\%) of adverse haemodynamic response to intubation in patients undergoing cardiac surgery, who had received midazolam-ketamine to induce anaesthesia. Ramsubramanian et al. ${ }^{26}$ in a group of healthy young women, found iv midazolam in doses up to 0.125 $\mathrm{mg} \cdot \mathrm{kg}^{-1}$ prior to induction to be unreliable in preventing increases in heart rate or blood pressure.

Recently, Munro et al. ${ }^{18}$ used premedication with oral diazepam and clonidine and demonstrated attenuation of the increases in blood pressure, heart rate and rate pressure product associated with induction of anaesthesia with iv ketamine $\left(2 \mathrm{mg} \cdot \mathrm{kg}^{-1}\right)$. Although they administered a fixed dose of clonidine $(0.3 \mathrm{mg})$ with diazepam (10 $\mathrm{mg})$, our results are comparable.

In conclusion, premedication of healthy patients with oral clonidine effectively attenuates but does not eliminate the hyperdynamic response associated with induction of anaesthesia with ketamine. The combination of clonidine and ketamine appears to be well tolerated and is not associated with a greater incidence of psychological phenomena than ketamine alone. It is possible that newer, more potent alpha $a_{2}$ adrenergic agonists under development may be more effective in completely antagonizing these undesirable haemodynamic effects.
References

1 Reves JG, Fragen RJ, Vinik HR, Greenblatt DJ.

Midazolam: pharmacology and uses. Anesthesiology 1985; 62: 310-24.

2 Stoelting RK. Pharmacology and Physiology in Anesthetic Practice. Philadelphia: JB Lippincott 1987; 69-101.

3 Corssen G. Miyaska M, Domino EF. Changing concepts in pain control during surgery: dissociative anesthesia with Cl-581. A progress report. Anesth Analg 1968; 47: 746-59.

4 White PF, Way WL, Trevor AJ. Ketamine - its pharmacology and therapeutic uses. Anesthesiology 1982; 56: 119-36.

5 Tweed WA, Minuck $M$, Mymin D. Circulatory responses to ketamine anesthesia. Anesthesiology 1972; 37: 613-9.

6 Lilburn JK, Dundee JW, Moore J. Ketamine infusions: observations on technique, dosage and cardiovascular effects. Anaesthesia 1978; 33: 315-21.

7 Issac $L$. Clonidine in the central nervous system: site and mechanism of hypotensive action. J Cardiovasc Pharmacol 1980; 2: S5-S20.

8 Kaukinen S, Pyykkö K. The potentiation of halothane anaesthesia by clonidine. Acta Anaesthesiol Scand 1979; 23: 107-11.

9 Bloor BC, Flacke WE. Reduction in halothane anesthetic requirement by clonidine, an alpha-adrenergic agonist. Anesth Analg 1982; 61: 741-5.

10 Ghignone M, Calvillo $O$, Quintin L. Anesthesia and hypertension: the effect of clonidine on perioperative hemodynamics and isoflurane requirements. Anesthesiology 1987; 67: 3-10.

11 Flacke JW, Bloor BC, Flacke WE, et al. Reduced narcotic requirement by clonidine with improved hemodynamic and adrenergic stability in patients undergoing coronary bypass surgery. Anesthesiology 1987; 67: 11-9.

12 Ghignone $M$, Quintin L, Duke PC, Kehler CH, Calvillo $O$. Effects of clonidine on narcotic requirements and hemodynamic response during induction of fentanyl anesthesia and endotracheal intubation. Anesthesiology 1986; 64: 36-42.

13 Orko R, Pouttu J, Ghignone M, Rosenberg PH. Effect of clonidine on haemodynamic responses to endotracheal intubation and on gastric acidity. Acta Anaesthesiol Scand 1987; 31: 325-9.

14 Pouttu J, Scheinin B, Rosenberg PH, Vïnamäki O, Schei$\operatorname{nin} M$. Oral premedication with clonidine: effects on stress responses during general anaesthesia. Acta Anaesthesiol Scand 1987; 31: 730-4.

15 Amend JF, Klavano PA, Stone EC. Premedication with xylazine to eliminate muscular hypertonicity in cats during ketamine anesthesia. Veterinary Medicine and Small Animal Clinician 1972; 67; 1305-7.

16 Van Pelt LF. Ketamine and xylazine for surgical anesthesia in rats. J Am Vet Med Assoc 1977; 171: 842-4. 
17 White GL, Holmes DD. A comparison of ketamine and the combination ketamine-xylazine for effective surgical anesthesia in the rabbit. Lab Anim Sci 1976; 26: 804-6.

18 Munro HM, Sleigh JW, Paxton LD. The cardiovascular response to ketamine: the effects of clonidine and lignocaine. Acta Anaesthesiol Scand 1993; 37: 75-8.

19 Reich $D L$, Silvay $G$. Ketamine: an update on the first twenty-five years of clinical experience. Can J Anaesth 1989; 36: 186-97.

20 Lundy PM, Lockwood PA, Thompson G, Frew $R$. Differential effects of ketamine isomers on neuronal and extraneuronal catecholamine uptake mechanisms. Anesthesiology 1986; 64: 359-63.

21 Dundee JW, Wyant GM (Eds.). Intravenous Anesthesia. New York: Churchill Livingstone 1988; 135-59.

22 Lilburn JK, Moore J, Dundee JW. Attempts to attenuate the cardiostimulatory effects of ketamine. Anaesthesia 1978; 32: 499-505.

23 Dundee JW, Lilburn JK, Moore J. Attempted reduction of the cardiostimulatory effects of ketamine by labetalol. Anaesthesia 1978; 32: 506-11.

24 Tuman KJ, Keane DM, Spiess BD, Mc Carthy RJ, Silins $A l$, Ivankovich $A D$. Effects of high-dose fentanyl on fluid and vasopressor requirements after cardiac surgery. J Cardiothorac Anesth 1988; 2: 419-29.

25 Marlow R, Reich DL, Neustein S, Silvay G.

Haemodynamic response to induction of anaesthesia with ketamine/midazolam. Can J Anaesth 1991; 38: 844-8.

26 Ramsubramanian $R$, Rawle PR, Verma $R$. Attenuation of psychological effects of ketamine anesthesia by midazolam: a dose-response study. Anesth Analg 1989; 68: S231. 